\title{
Linking Education with Industry: Pedagogical models from lighting design
}

\author{
Abimbola O. Asojo \\ University of Minnesota \\ aasojo@umn.edu
}

\begin{abstract}
This article discusses an industry collaboration where interior design students designed and built light fixtures that exemplified a company's product line via social media. The design challenge was to conceptualize and build a fixture that uses sustainable materials that exemplifies Groovy stuff's product line. Groovy stuff provided the class with a bill of materials kit and feedback via Facebook. Student's final fixture prototypes were informed by research, collaboration with Groovy stuff via social media, parametric modeling, and digital fabrication techniques.
\end{abstract}

Keywords: Industry collaboration; lighting design; interior design; sustainability

eISSN: 2398-4295 @ 2016. The Authors. Published for AMER ABRA by e-International Publishing House, Ltd., UK.. This is an open access article under the CC BY-NC-ND license (http://creativecommons.org/licenses/by-nc-nd/4.0/). Peer-review under responsibility of AMER (Association of Malaysian Environment-Behaviour Researchers), ABRA (Association of Behavioural Researchers on Asians) and CE-Bs (Centre for Environment-Behaviour Studies), Faculty of Architecture, Planning \& Surveying, Universiti Teknologi MARA, Malaysia.

https://doi.org/10.21834/ajbes.v1i1.17 


\subsection{Introduction}

Current design industry trends require the development of competencies in collaboration in academia. Therefore, in order to expose Interior Design students to multiple view points, the 2014 Council for Interior Design Accreditation (CIDA) Standard 5 now requires that

Entry-level Interior Designers engage in multi-disciplinary collaborations... Students have awareness of a) team work structures and dynamics, b) the nature and value of Integrated design practice (p.15).

Furthermore, Standard 5 program expectations are Interior design program includes learning experiences that engage students in c) multi-Disciplinary collaboration, leadership, and team work, d) interaction with multiple Disciplines representing a variety of points of view and perspectives (p.15).

Overall, this CIDA standard emphasizes the importance of collaboration and integrated practices to the academy today. Another requirement, CIDA 2011 Standard 9 focuses on space and form, the expectations are;

Entry level interior designers apply elements and principles of two and three dimensional Design... Students effectively apply the elements and principles of design to: a) two-Dimensional design solutions, b) three-dimensional design solutions... (p. 19).

This article discusses pedagogical experiences from an academic and industry collaboration where interior design student designed and built light fixtures that exemplified Groovy stuff's product line. New technologies such as collaboration via social media, parametric modelling and digital fabrication techniques informed the process.

\subsection{Literature Review}

The American Institute of Architects (AIA)

New modes of project design and delivery have created an opportunity for professionals and eduาcators alike to reassess the dynamics of practice and education...This integrated approach, enabled by inte $\urcorner$ grated design tools, is resulting in enhanced communica?tion, more comprehensive and coordinated documents and improved collaborative teams (p. 1).

These trends imply that design programs must prepare students for future roles in integrated practices. The benefits of integrated project delivery methods in ac 7 ademic settings are profound. The most significant benefit is the opportunity for collaboration in the curriculum. The AIA notes other benefits such as

Empowering each student's individual capacities and abilities, responding to students different learning styles, engaging students in shared leadership opportunities and roles, providing opportunities for interdisciplinary study throughout the curriculum and across the campus, and encouraging crosspollination with engineering, business and con struction colleges/departments to demonstrate the value of integrated design and delivery processes (p.1).

These benefits apply to interior design programs, and integrated practices offer implications for interior design pedagogy. The implications are numerous for interior design programs. For example, how can interior design educators teach students to prepare them to 
work in collaborative environments? This paper takes a pragmatic approach. The author presents practical examples from an interior design academic setting, where students collaborate with industry to design and build light fixtures in a lighting design second and third year course. Their experience illustrates the importance and success of connecting academia with industry and effective ways to engage in these types of discourse.

\subsection{Methodology}

This section discusses pedagogical experiences from an academic and industry collaboration. The task was for interior design students to design and build light fixtures that exemplified Groovy stuff's product line. New technologies such as feedback via social media, parametric modeling software (Revit), and digital fabrication techniques informed the collaborative design process. In spring 2013 and fall 2014, second and third year interior design students in a lighting design course collaborated with Groovy stuff, a wholesale manufacturer and supplier of traditional rustic home furnishings and décor based in Dallas, Texas. The goal of the project was to design a light fixture that utilizes or reconfigures reclaimed material that exemplifies the company's product line. Students were encouraged to use sustainably harvested woods such as plantation Teak and Asian Mahogany. Their design presentation boards and prototype models were then required to be displayed for retailers, interior designers and attendees in High Point Market, Las Vegas in 2013 and North Carolina in 2014 for a competition. The author shares findings about pedagogy, outcomes, as well as, pros and cons of this industry collaboration to serve as a model for other interior design educators.

\subsection{Pedagogical goals}

The main goal of the interior design lighting design course at the University of Minnesota is to introduce lighting as a dynamic element impacting interiors. Other goals include increasing students awareness of lighting as an evocative design element, balancing aesthetics and functional issues in lighting, gaining knowledge of a variety of current lighting types and resources, developing technical competence in delivering a lighting design solution and understanding energy conservation and environmental issues related to lighting. Lecture presentations focus on psychological aspects of lighting, color, light quality, light sources, photometry, codes, daylighting, energy conservation, and how lighting impacts health and wellbeing. Assignments and design projects emphasize the integration of lighting with interior and architectural elements, techniques in lighting design, fixture design, and exploration of computer visualization. Building codes that affect life safety and energy codes are introduced. The light fixture design project from this course formed the context for this paper.

\subsection{The design challenge}

The design challenge for the light fixture project was to collaborate with industry and design a fixture that uses reclaimed materials and exemplifies Groovy stuff product line. Groovy stuff Company was founded by Chris Bruning. The company produces sustainable residential furnishings out of reclaimed teakwood. The company is based in Dallas, Texas. The company sponsors a program titled the University Hall of Innovation and Job Creation which focuses on connecting academia with industry. The light fixture design project discussed in this paper was part of the program in spring 2013 and fall 2014. The goal was to have students' 
designs and prototypes displayed to participate in High Point in Las Vegas and North Carolina, an exhibit for retailers, interior designers and attendees to vote most marketable and most likely to show a profit. The judging process for the challenge involved two stages. The first involved the popular vote based on the prototype and presentation boards provided by the students. The second involved rewarding students royalty based on product orders after the exhibition. At the inception of the project, Groovy stuff provided students with their license agreement which contracts directly with the student as a professional. Students were also provided raw materials kit at the inception of the project to help familiarize the students with the reclaimed parts from the company's line. Students were required to join a Facebook group created for the class to upload ideation sketches, renderings, technical drawings and presentation drawings for feedback from industry.

The project occurred over a five-week period with class meeting two days a week in the spring semester. On day one, students were introduced to the project and the class opened and reviewed the raw material kit package from Groovy stuff. Next, they reviewed the design brief and researched the Company, their location, services, target audience, clients, market trends and styles. At the end of class, each student was required to outline a design purpose and outline goals for their design solution. On day two, students were introduced to the digital fabrication and woodshop lab in the College of Design. The digital fabrication lab provides students in the College of Design with digital tools such as CNC routers, laser cutters and 3D printers for hands on exploration of design ideas. The woodshop provides students a wide selection of power and hand tools for working on wood, metals and other materials. This introduction at the inception of the project offered students opportunities to explore materials and fabrication techniques in their design solution.

On day three and four, using the information students researched and their purpose and goals students began sketching and creating rough conceptual ideas. Each student was required to post up to fifteen different ideation sketches on the Facebook class group in each student's individual folder for comments, feedback, and direction from industry by the end of class on day four. The advantage of posting the sketches on Facebook was that industry, instructor and fellow students were able to give feedback and comment on the sketches fairly quickly in an effective way digitally. On day five, students continued to refine their sketches and ideation in preparation for mid-project presentation scheduled for the next class period. On day six, students presented their best three options for consideration and through feedback from practitioners, instructor and peers, and finally, students selected the option to develop as their final design. From day seven to ten, students built their final design and prepared display boards of their designs. The requirements for their final presentations were

(i) A 20" X 30" display board illustrating concept, presentation drawings, breakaway axonometric, and pictures.

(ii) A half-scale model for a table lamp or a quarter-scale model for a floor lamp

(iii) A 42" pedestal for display at High Point, Las Vegas

(iv) Assembly files in Computer Aided Design (CAD) format. The CAD files included plan, elevation, section, breakaway axonometric.

On day eleven, students presented their final designs via web conferencing to industry. Students boards, pedestals and models were subsequently mailed for exhibition and 
competition at the University Hall of Innovation and Job Creation program in High Point Market in April 2013 and November 2014.

\subsection{Results and Discussions}

Fifteen students from the class elected to participate in the exhibition and competition in High point, Las Vegas in 2013. Twenty-two students from the class participated in the exhibition and competition in High point, North Carolina in 2014. Five student projects are described next. One student designed a lamp named "Mixed emotions" (Figure 1 and 2). The inspiration for the Mixed Emotions light fixture was the challenge of blending the;

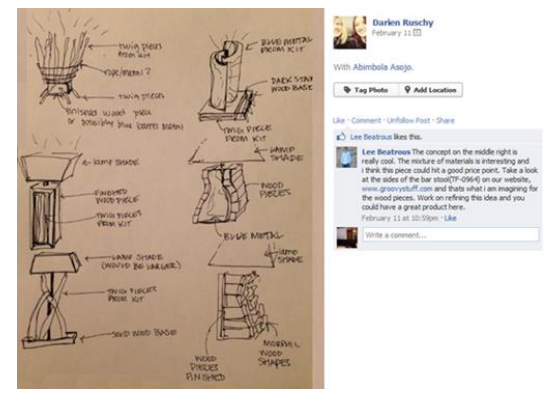

Figure 1: Conceptual Sketches

(Source: Ruschy, 2013)

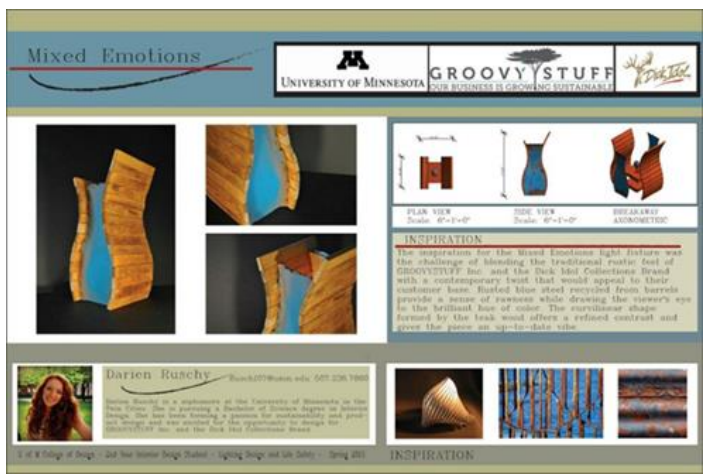

Figure 2: Light Fixture Design

(Source: Ruschy, 2013)

Traditional rustic feel of Groovy stuff and the Dick Idol Collections Brand with a contemporary twist that would appeal to their customer base. Rusted blue steel recycled from barrels provide a sense of rawness while drawing the viewer's eye to the brilliant hue of color. The curvilinear shape formed by the teak wood offers a refined contrast and gives the piece an up-to-date vibe (Ruschy, 2013).

Another student designed a lamp named "Unbounded Comfort" (Figure 3). 


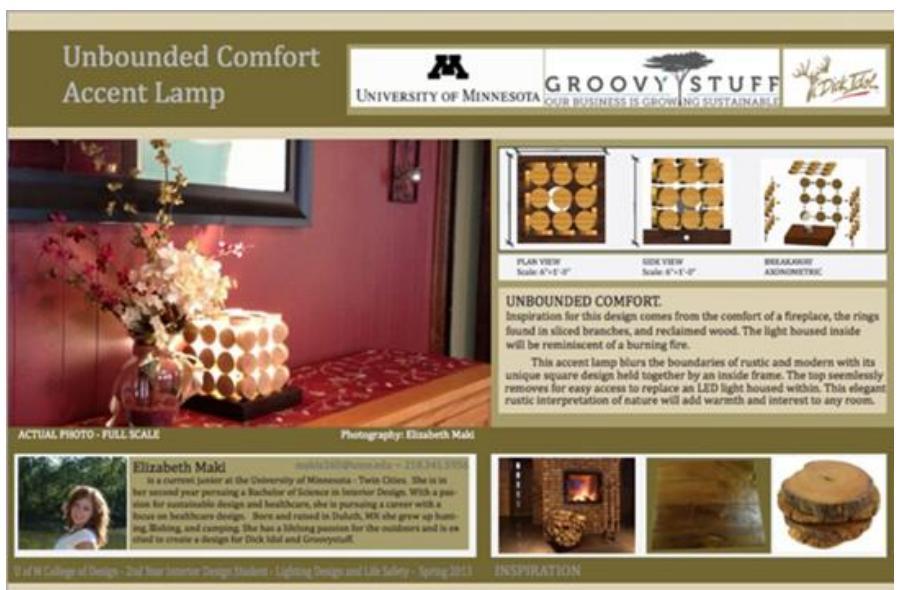

Figure 3: Light Fixture Design

(Source: Maki, 2013)

Inspiration for the design came from a fireplace, the rings found in sliced branches, and reclaimed wood. The light housed inside is reminiscent of a burning fire. This accent lamp blurs the boundaries of rustic and modern with its unique Square design held together by an inside frame. The top seamlessly removes for easy access to replace the LED fixture (Maki, 2013).

One student won the challenge for her Montana table lamp which

Expresses the modern rustic spirit of Dick Idol through its big-sky silhouette and rough, Earthy texture from the reclaimed steel drums found in the Groovy stuff Moonshine Collection.

\section{About her design one student noted}

As a designer intrigued by the possibilities of repurposing materials, I identify with Chris Bruning's commitment to sustainability and transformation. With direction from the Groovy stuff team, we discovered the key to a successful finished product was exploiting the inherently positive characteristics of each reclaimed material (Deline, 2013).

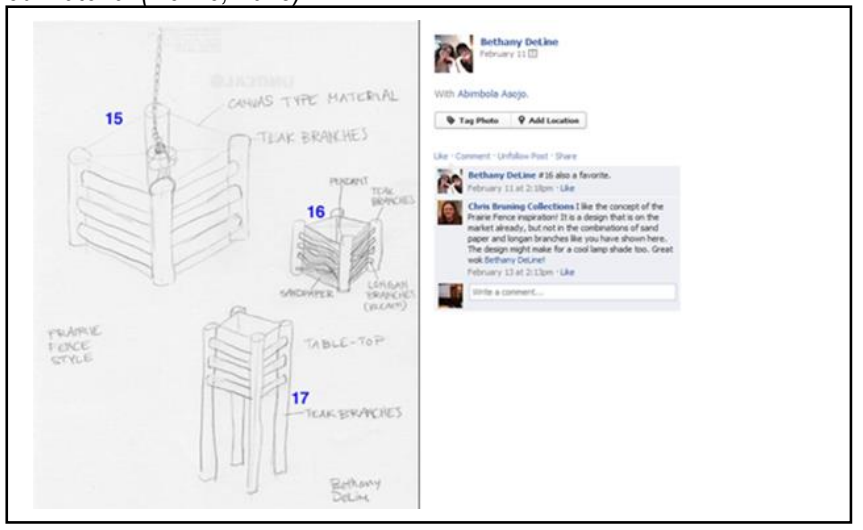

Figure 4: Conceptual Sketches

(Source: Deline, 2013) 
Figure 4 and 5 illustrate the student's design. She was awarded a prize of $\$ 250$ for winning the challenge. Another student on her design named "Entwine lamp" noted

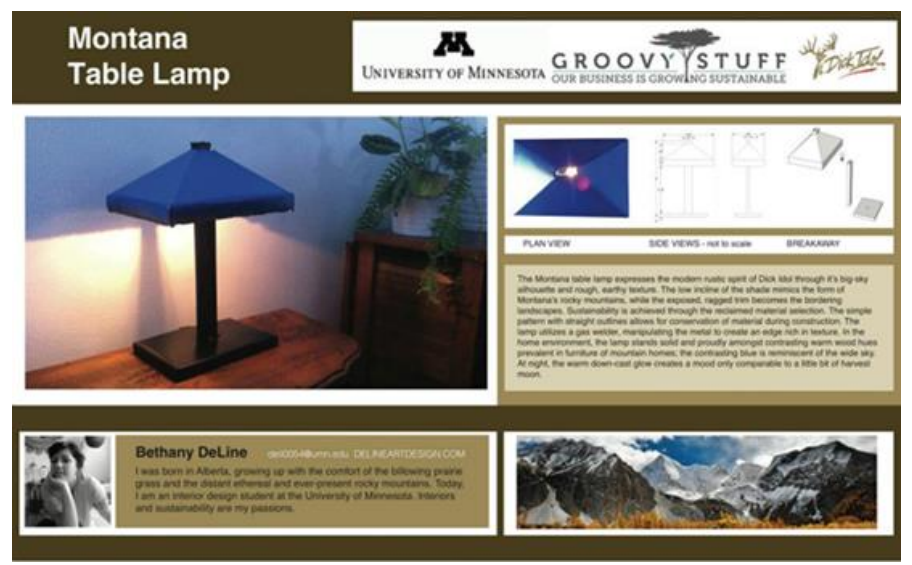

Figure 5: Light Fixture Design

(Source: Deline, 2013)

The lamp adds a primal sentiment to the room in which it is placed. It is built of reclaimed wood. Entwine will represent the connections between the former life of its materials and the future of the lamp as a whole. There will be pieces that are interconnecting at the top as well as a strong sturdy base. An organized structure will give way to the twists and turns of the wood, combining the many backgrounds of the pieces into one. A teak tree branch holding fast with the styles of Groovy stuff and the Dick idol brand will hold up the luminaire. Short teak sticks and twigs will interface above the rest to create the shade. Each piece will play a part in creating the uniqueness of the Entwine lamp (Figure 6 and 7).

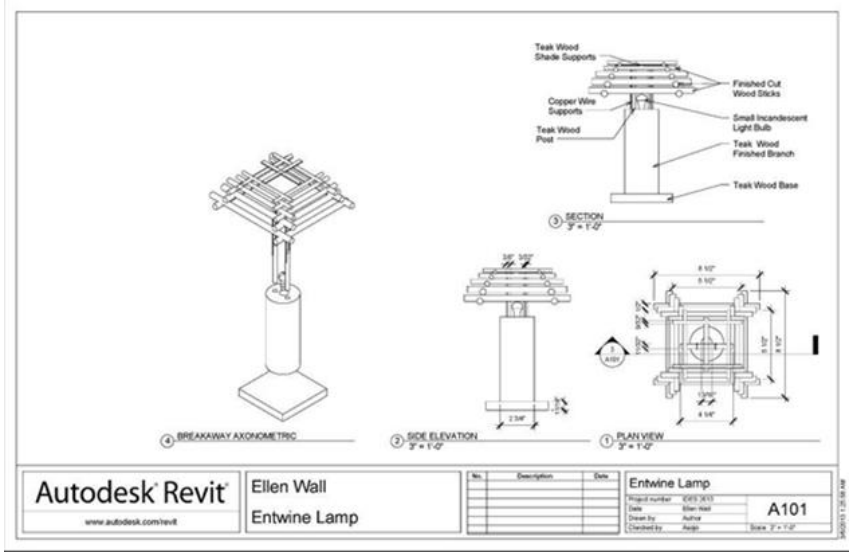

Figure 6: Light Fixture Design

(Source: Wall, 2013) 


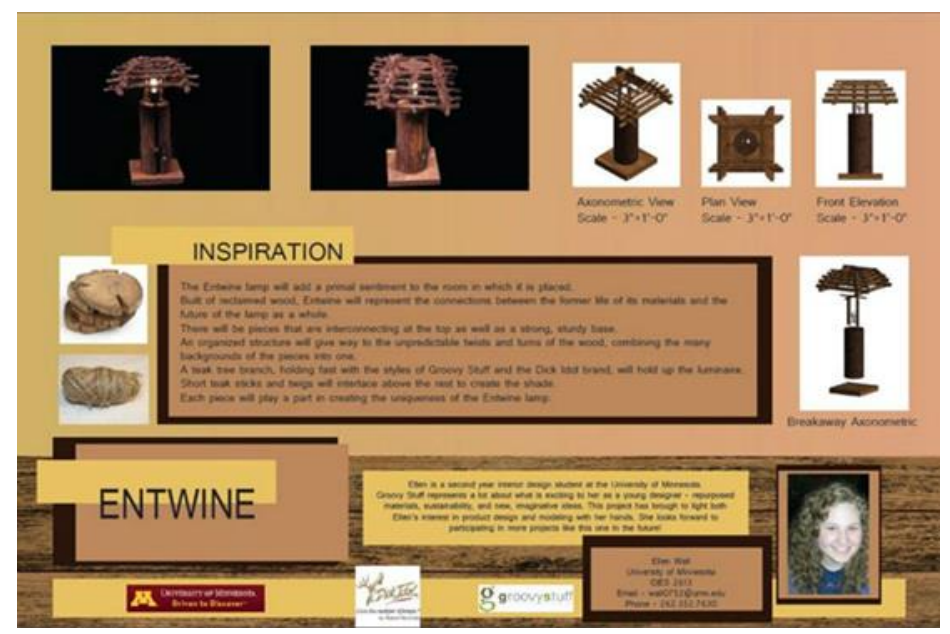

Figure 7: Light Fixture Design

(Source: Wall, 2013)

Another student on her design named Tangled table lamp (Figure 8) noted:

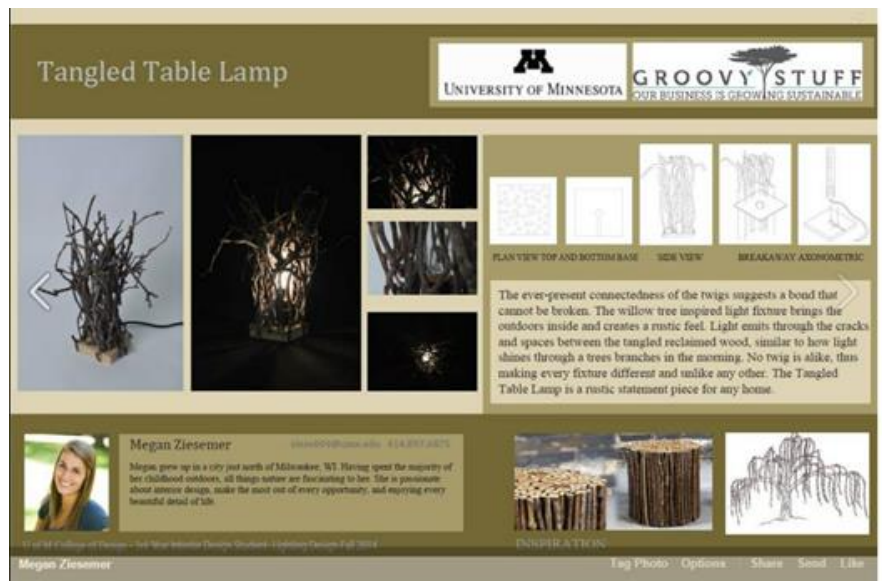

Figure 8: Light Fixture Design

(Source: Ziesemer, 2014)

The willow tree inspired light fixture brings the outdoors inside and creates a rustic feel. Light emits through the cracks and spaces between the tangled reclaimed wood, similar to how light shines through a tree's branches in the morning. No twig is alike, thus making every fixture different and unlike any other. The Tangled Table Lamp is a rustic statement piece for any home (Ziesemer, 2014). 


\subsection{Pros and cons of the experience}

Technologies for collaboration via social media in an academic setting are very recent, and current generation of college student often referred to as millennials are technologically savvy and vast in sharing information via social media. Therefore, students in the class were comfortable with sharing their ideation process and designs on Facebook. Using the Facebook class group for communication and obtaining feedback on ideation and presentation drawings supported multiple learning styles. It offered students effective ways of receiving feedback from industry, instructor and peers in a timely, visual and collaborative manner. It was also significant that it allowed for sharing of ideas between instructor and students, students and peers, and most importantly between students and industry. The requirement of uploading sketches and ideation drawings to the Facebook page improved students sketching skills. The Facebook group served as a repository of their design ideas. It allowed the ideation and sketching process to be iterative.

Revit is a Building Information Modeling (BIM) software which students used to digitally model their solutions. The software was very effective in synthesizing and visualizing their design solutions in three-dimension. Revit's strength in parametric modeling and bidirectional associativity was beneficial in the design process. In Revit, Parametric objects are "smart objects" that can change in size, material, and graphic look but are constantly the same object. Bidirectional associativity works such that embedded relationships are created between different objects in a model, so that as things are created and attached, the other objects connected to it also adapts and changes. The digital models simplified constructability of students' designs. They utilized digital fabrication techniques using the laser printers and $3 \mathrm{~d}$ printers, as well as woodshop tools to build their models. The license agreement the students signed was directly with Groovy stuff and one of their objectives was to treat the students professionally, as they were contracted for their work as professionals. Students had the opportunity to win popular vote and also earn royalty if their product was manufactured. Other positive aspects of this project were accomplishing a product from ideation to reality while collaborating with practice. Students design parameters were based on the kit of materials sent to the class from industry.

One limitation of the experience was the short timeline of fitting the light fixture design project with other class requirements in the course. This project had to be accomplished in five weeks. Another limitation was introducing students to the digital fabrication lab and woodshop at the sophomore level and accomplishing the light fixture project the same semester. Another limitation was the large size of the class which had 25 students. However, feedback from industry helped with accomplishing and giving students constructive feedback in a timely manner. Another limitation was at the end of the project, only 15 students eventually agreed to send their fixtures to the competition. Some students got very attached to their creations and did not want to part with it.

\subsection{Conclusion}

Overall this pedagogical experience illustrates numerous benefits from an academic and industry collaboration. Technologies such as collaboration via social media, parametric modeling, and digital fabrication techniques informed the design process that students used to design and build light fixtures. This experience has some implications. As the current rising 
trends of simultaneous design, engineering and construction planning are forcing collaboration and constant communication throughout the life cycle of a project, educational models must adapt to the demands of the profession and shift towards teaching and encouraging academic and industry collaboration. The author hopes this article will serve as a model for design educators interested in collaboration with industry.

\section{Acknowledgement}

The author would like to acknowledge Chris Bruning and Groovy stuff for providing the class with this collaboration opportunity, a bill of materials kit and feedback via Facebook.

\section{References}

American Institute of Architects (2007). Draft White Paper, Part II-Integrated Project Delivery Methods. Retrieved October 20, $2008 \mathrm{http}: / /$ blog.aia.org/whitepaper/2007/09/draft white paper for the naab 5.html

Asojo, A. O. \& Pober, E. F. (2009). Building Information Modeling (BIM) Strategies: Pedagogical Models for Interior Design. Design Principles and Practices: An International Journal, 3(2), 159-167.

Asojo, A. O. \& Pober, E. (2007). Digital Design Communication Techniques in Interior Design Education. Interior Design Educators Council Southwest Regional Conference Proceedings, Waco, Texas, October 2007 p. 21-27.

Brake, A. G. (2012). Power Tools. Retrieved June 10, 2013 http://www.iida.org/content.cfm/power-tools.

Council for Interior Design Accreditation. (2013). Council for Interior Design Accreditation: Professional Standards. Grand Rapids: Author.

Demchak, G., Dzambazova, T. \& Krygiel, E. (2008). Introducing Revit Architecture 2009 BIM for Beginners. Indianapolis: John Wiley.

Home furnishings Business strategies for furniture retailer (2013). Groovy stuff Names Design Challenge Winners. Retrieved May 16, 2013 http://www.hfbusiness.com/article/4-design-students-winners Groovy stuff-furniture-designchallenge/2

National Council for Interior Design Qualification (2008). Who we are: NCIDQ Definition of Interior Design. Retrieved October 20, 2008 from http://www.ncidq.org/

Stine, D.J. (2013). Commercial Design Using Autodesk Revit Architecture. Mission: SDC Publications.

Wardono P., Hibino, H. \& Koyama S. (2010). Effects of Interior Colors, Lighting and Decors on Perceived Sociability, Emotion and Behavior Related to Social Dining. Procedia - Social and Behavioral Sciences, 38(2012), 362 - 372. 